\title{
VISUALISASI DATA SENSOR PADA SISTEM PEMANTAUAN SUHU DAN KELEMBABAN RUANGAN BERBASIS ANTARMUKA WEB
}

\author{
Qisthi Alhazmi Hidayaturrohman ${ }^{1}$, Prasetyo Yuliantoro ${ }^{2}$, Reda Rizal ${ }^{3}$ \\ Fakultas Teknik-Universitas Pembangunan Nasional Veteran Jakarta, Indonesia ${ }^{13}$ \\ Institut Teknologi Telkom Purwokerto ${ }^{2}$ \\ qisthialhazmi@upnvj.ac.id ${ }^{1}$
}

\begin{abstract}
Abstrak
Teknologi internet of things telah menjadi salah satu teknologi yang berperan dalam revolusi industri 4.0. Tidak hanya sebatas komunikasi data antar perangkat melalui jaringan komunikasi data protokol internet, pada perangkat IoT juga diperlukan antarmuka yang baik dalam memvisualisasikan data yang telah diterima oleh node server, sehingga pengguna dapat dengan mudah memahami data yang bertukar atau berkomunikasi di dalam sistem. Pada penelitian yang dilakukan oleh Yuliantoro, et. al. perangkat IoT yang dirancang hanya sebatas komunikasi data antar perangkat, di mana web server sebagai node server yang menerima seluruh data sensor. Perancangan sistem visualisasi data pada penelitian ini, dirancang menggunakan skrip PHP dan web server yang terhubung dengan perangkat nodeMCU secara lokal (WLAN). Data sensor dari nodeMCU dikirimkan ke server lalu hasilnya akan ditampilkan secara visual dengan antarmuka website. Berdasarkan hasil dari penelitian ini, data yang divisualisasi sudah menampilkan data sensor secara keseluruhan, dengan jeda waktu yang sudah sesuai dengan jeda waktu yang dikirimkan oleh NodeMCU yaitu 60 detik.
\end{abstract}

Kata kunci: Visualisasi data, WSN, IoT, Web Server

\begin{abstract}
The internet of things technology has become one technology that plays a role in the industrial revolution 4.0. Not only limited to the data communication between devices over internet protocol communication data networks, but on the IoT device is also need the proper interface to visualize the sensor data which has received by the server node, and with that result, the user can understand easily and get insight from those data which has an exchange or communicate each other on the system. In the previous research by Yuliantoro, et. al., the IoT device was designed only to communicate to other devices, where the web server as a server node was designed to receive the sensor data. The design of the visualize system in this research, designed by the PHP script and web server which is connected to the NodeMCU in a wireless local area network or WLAN. The sensor data from NodeMCU sent to the server, then the result will be shown visually by the website interface. Based on the results of this study, the visualized data has been shown the full sensor data, with the delay is following the delay of the NodeMCU, 60 seconds.
\end{abstract}

Keywords: Data Visualization, WSN, IoT, Web Server

\section{PENDAHULUAN}

Di era industri 4.0 ini, teknologi Internet of Things atau IoT telah menjadi salah satu teknologi yang menjadi tren saat ini. Teknologi IoT menghubungkan setiap perangkat elektronik, umumnya berupa sensor, untuk saling berkomunikasi satu sama lain, saling bertukar data [1]. Tidak sedikit industri juga dunia akademik telah menerapkan teknologi IoT di lingkungannya, dengan mengubah teknologi konvensional yang sudah tersedia menjadi teknologi IoT. Degan teknologi IoT, data dapat dikumpulkan dalam satu wadah yang dikenal sebagai coordinator node atau server yang menyimpan keseluruhan data yang ada di dalam lingkungan tersebut. Umumnya, diperlukan 
sistem, baik berbasis web maupun mobile, yang digunakan untuk menampilkan hasil-hasil data yang terkumpul di dalam server tersebut. Dikenal sebagai sistem visualisasi data sensor, yang berguna untuk menampilkan data-data dari sensor yang terhubung dalam satu jaringan dengan node di lingkungannya [2]. Kebutuhan akan sistem visualisasi data sensor tersebut menjadi alasan penulis dalam melakukan penelitian ini.

Permasalahan yang umum terjadi dalam perancangan sistem visualisasi data adalah bagaimana data yang tersimpan di dalam server dapat disajikan dengan baik, sehingga pembaca atau user dapat memahami data dari sistem IoT yang telah diimplementasikan. Dalam hal ini, sistem pemantauan suhu dan kelembaban yang telah dirancang menggunakan teknologi IoT belum memiliki sistem visualisasi data sensor yang secara real-time telah tersimpan di dalam web server. Sistem visualisasi bertujuan untuk memberikan informasi secara grafik dari data sensor suhu dan kelembaban yang tersedia. Penelitian ini dibatasi hanya pada visualisasi grafis untuk data sensor yang telah masuk ke dalam basis data server dan ditampilkan di antarmuka website, sehingga tidak membahas terkait komunikasi data yang terjadi di dalamnya.

\section{TINJAUAN PUSTAKA}

Pada penelitian yang dilakukan oleh Yuliantoro, et al., sistem pemantauan suhu dan kelembaban ruangan indoor dilakukan menggunakan perangkat berbasis ESP8266 (NodeMCU) yang dihubungkan dengan komputer yang sudah terinstall web server di dalamnya [3]. Akan tetapi, pada penelitian tersebut, data sensor hanya disimpan secara real-time di basis data web server tersebut, sehingga belum ditampilkan secara grafis menggunakan web server tersebut. Pada penelitian ini, penulis melakukan visualisasi data sensor dari alat yang telah dirancang oleh Yuliantoro, et.ak. Selanjutnya, Qisthi dan Nur Sultan telah mengimplementasikan teknik visualisasi data menggunakan antarmuka website pada alatnya yaitu mobil penjelajah yang dirancang menggunakan perangkat Raspberry-Pi [4]. Pada penelitian tersebut, teknik visualisasi data yang dilakukan hanyalah sebatas text field saja, sehingga belum dibuat dalam bentuk visual grafis. Penulis menggunakan metode yang diimplementasikan oleh Qisthi dan Nur Sultan dalam menampilkan data sensor di basis data yang telah dirancang, yaitu teknik GET data dari basis data tersebut.
Berdasarkan kedua sumber utama tersebut, penulis menggunakan mikropengendali berbasis ESP8266 yaitu NodeMCU yang dirancang dan dihubungkan secara WLAN dengan komputer yang sudah terinstall web server di dalamnya. NodeMCU merupakan mikropengendali berbasis ESP yang sudah tertanam komunikasi Wi-Fi di dalamnya [5]. Komunikasi tersebut digunakan untuk mengirimkan data sensor dari perangkat mikropengendali ke web server untuk disimpan secara real-time ke basis data tersebut. Sensor yang digunakan adalah sensor DHT11 yang luarannya sudah terdapat suhu dan kelembaban, khususnya untuk ruangan [6]. Web server yang digunakan adalah web server berbasis Apache yang di dalamnya sudah tersedia MySQL untuk basis data. Web server tersebut berfungsi sebagai penyimpan data-data yang masuk dari node sensor dan juga sebagai penampil antarmuka web [7].

\section{METODOLOGI PENELITIAN}

Metodologi penelitian yang dilakukan oleh penulis adalah merancang sistem visualisasi data sensor dari sistem IoT yang sebelumnya telah dirancang oleh Yuliantoro, et. al. dengan menggunakan skrip PHP dan web server beserta basis data berbasis SQL. Adapun alir diaram penelitian penulisan ini adalah sebagai berikut:

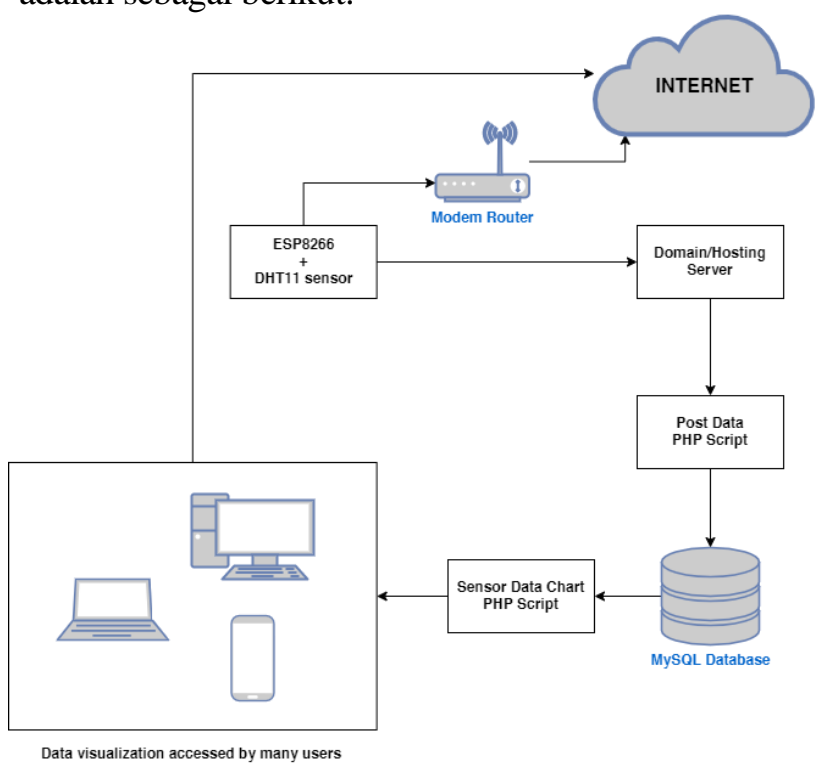

Gambar 1. Diagram Alir Penelitian

Penelitian ini merupakan kelanjutan dari penelitian yang telah dilakukan oleh Yuliantoro, et.al. [3]. Pada penelitian ini, penulis merancang sistem web services untuk menerima data sensor dari mikropengendali ke komputer yang sudah terinstall web server melalui jaringan wi-fi yang saling terhubung secara WLAN. Sensor yang dikirimkan dari mikropengendali, disimpan di dalam basis data 
berbasis MySQL dengan metode post data menggunakan bahasa pemrograman PHP. Data tersebut tersimpan secara real-time di basis data tersebut. Selanjutnya, data di basis data akan diambil oleh kompter server melalui skrip PHP untuk ditampilkan ke dalam halaman muka utama (index.php) dalam bentuk grafik visual. Proses pengambilan data dari basis data ke antarmuka web, menggunakan metode get data dengan skrip PHP. Data secara real-time akan diambil dari basis data untuk ditampilkan di antarmuka website, dan website setiap 5 detik akan melakukan refresh untuk memperbarui data yang tampil di grafis visual tersebut. Pengguna lain yang berada di dalam satu jaringan yang sama dapat mengakses antarmuka web tersebut dengan mengakses alamat IP server yang sudah disiapkan. Pengguna di luar jaringan dapat mengakses melalui alamat domain dari hosting server yang telah dirancang sebelumnya, akan tetapi, pada penelitian ini, tidak membahas terkait hak akses publik tersebut.

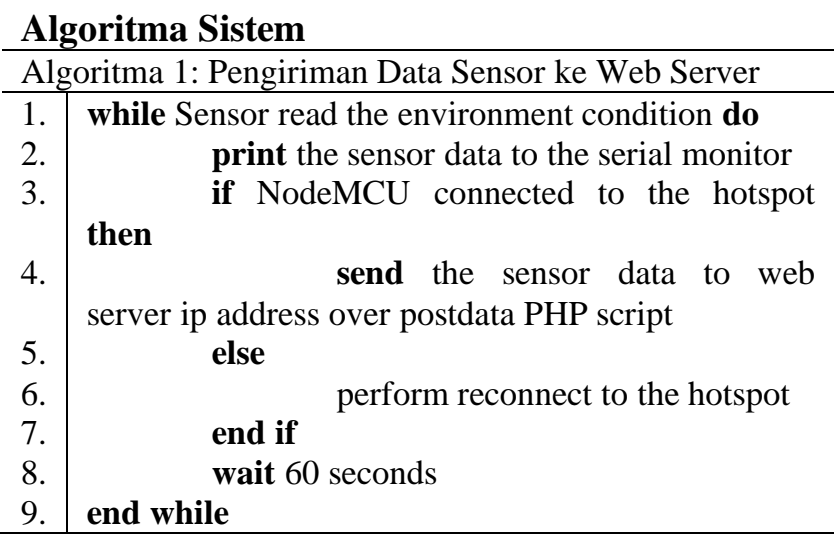

Pada Algoritma 1 di atas, mikropengendali berbasis ESP8266, NodeMCU, mengirimkan data ke web server untuk disimpan dan ditampilkan melalui skrip perintah PHP postdata. Lalu, NodeMCU memberikan delay atau waktu jeda selama 60 detik sebelum mengirimkan datanya kembali.

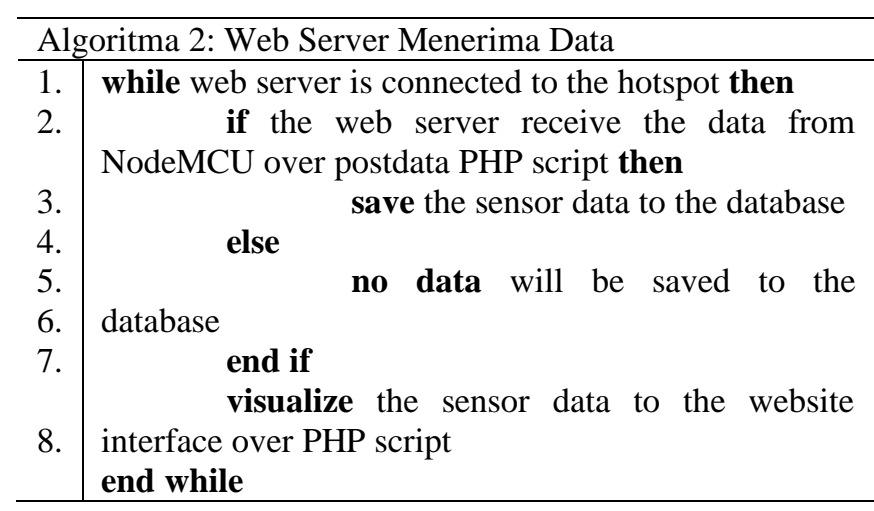

Pada Algoritma 2 di atas, web server menerima data dari NodeMCU dan menyimpannya data tersebut ke dalam basis data

yang sudah terinstall di dalam web server. Setelahnya, data tersebut ditampilkan melalui antarmuka web yang berdiri atas bahasa pemrograman PHP.

\section{ANALISIS DAN PEMBAHASAN DATA}

Hasil penelitian ini dibagi atas dua hal pembahasan, yaitu tentang data sensor di basis data yang menjelaskan hasil dari data sensor yang telah berhasil dikirimkan dari node sensor melalui perangkat NodeMCU dan node server. Basis data yang digunakan merupakan basis data berbasis SQL. Selanjutnya, untuk hasil penelitian yang kedua adalah hasil visualisasi data, yang berisikan tampilan visual berupa grafik melalui antarmuka website. Data yang divisualisasi tersebut merupakan data dari sensor yang sudah disimpan secara real-time di basis data. Proses visualisasi data juga dalam bentuk real-time.

\section{Data Sensor di Basis Data}

Sensor yang telah tertanam dalam mikropengendali berbasis ESP8266 mengirimkan data ke web server yang terhubung ke dalam satu jaringan komunikasi. Data sensor tersebut tersimpan di dalam basis data berbasis SQL yang sudah terintegrasi dengan web server tersebut. Adapun hasil tabel basis data adalah sebagai berikut:

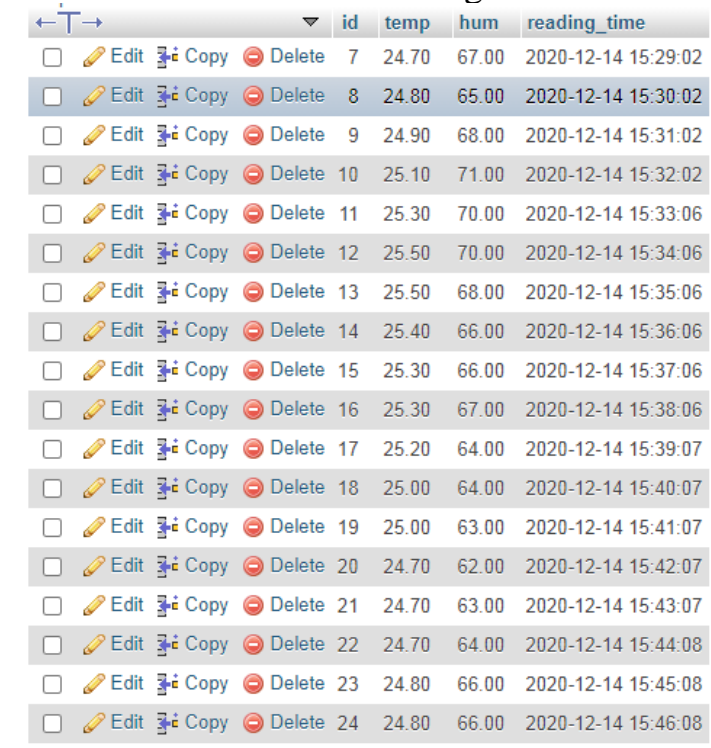

Gambar 2. Data Sensor di Basis Data

Pada basis data, data sensor disimpan dengan 4 baris keterangan yaitu id, temp, hum, dan reading_time, yang mana id sebagai nomor urut data yang masuk, temp adalah data suhu, hum adalah data kelembaban, dan reading_time adalah waktu data diterima oleh server. Berdasarkan dari pengamatan dari data yang diterima oleh sensor dan disimpan di dalam basis data, data dari sensor diterima setiap rentang 1 menit, meski pernah sesekali terjadi jeda waktu yang berbeda, namun 
tetap dalam rentang 1 menit atau 60 detik data diterima dari perangkat sensor ke server.

\section{Visualisasi Data di Antarmuka Website}

Data yang sudah tersimpan di dalam basis data secara real-time, selanjutnya dipanggil oleh skrip PHP untuk ditampilkan di dalam antarmuka website. Tampilan visual tersebut berupa tampilan grafik dari data sensor tersebut. Adapun hasil dari visualisasi data di antarmuka website tertuang pada Gambar 3 dan 4 dari komputer dan Gambar 5 dari smartphone.

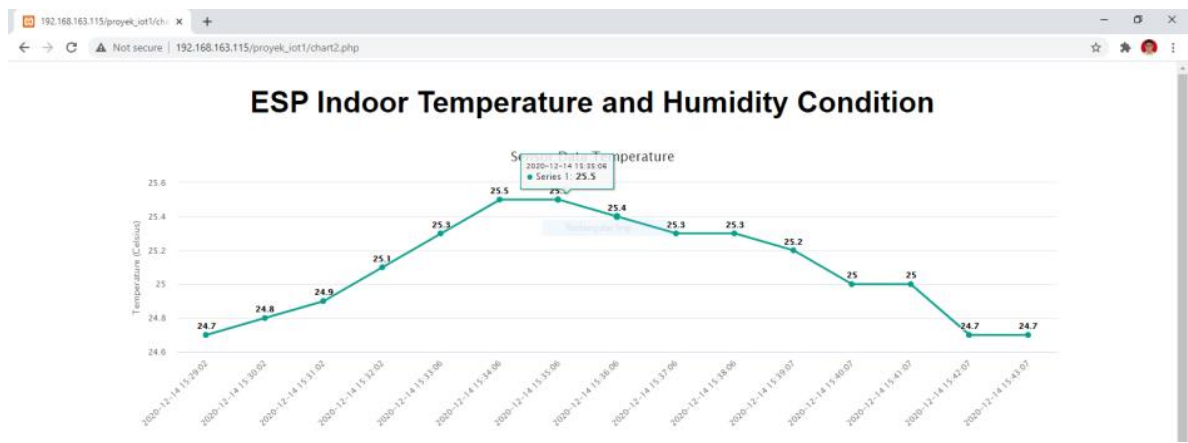

Gambar 3. Temperatur ruang dan cairan baterai

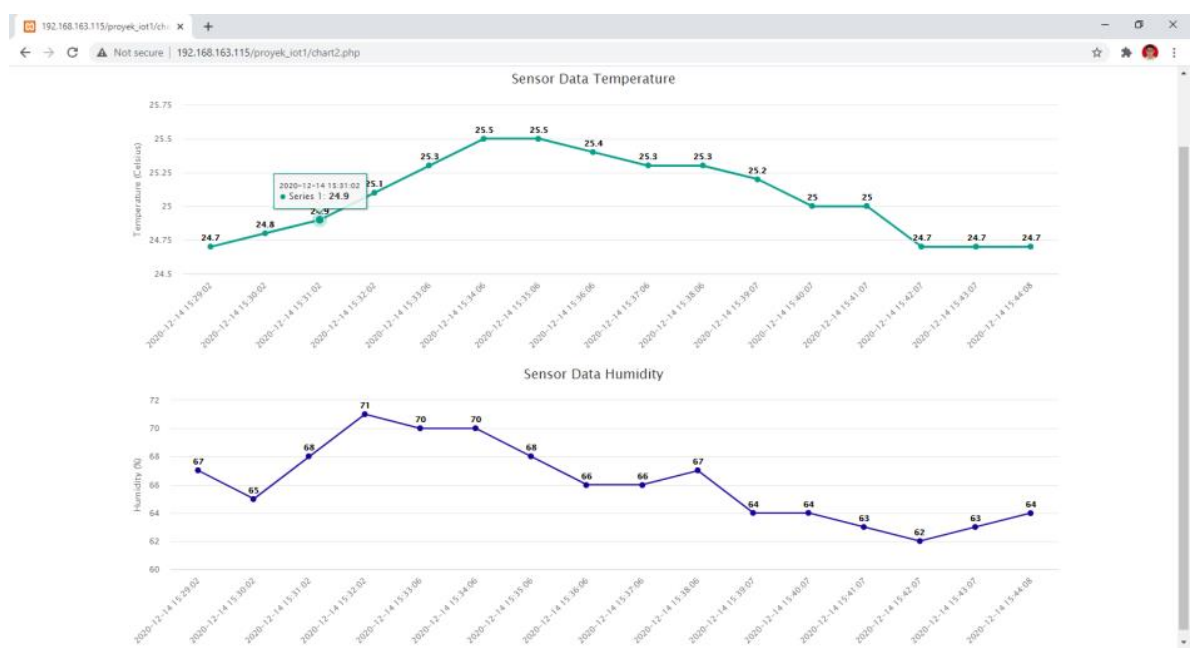

Gambar 4. Hasil Visualisasi Data di Antarmuka Website (Kelembaban)

Dari dua pengamatan hasil visualisasi dengan antarmuka website di atas, menunjukkan bahwa perubahan data, baik suhu maupun kelembaban, akan terlihat dari naik atau turunnya grafik visual tersebut. Data yang ditampilkan merupakan data yang diambil (GET) dari basis data sebelumnya. Pengambilan data dari basis data menggunakan perintah GET DATA skrip PHP. Selain hasil tampilan dapat diakses melalui perangkat komputer, juga dapat diakses dari perangkat telepon pintar (smartphone) dengan tampilan yang menyesuaikan ukuran layar (responsive).
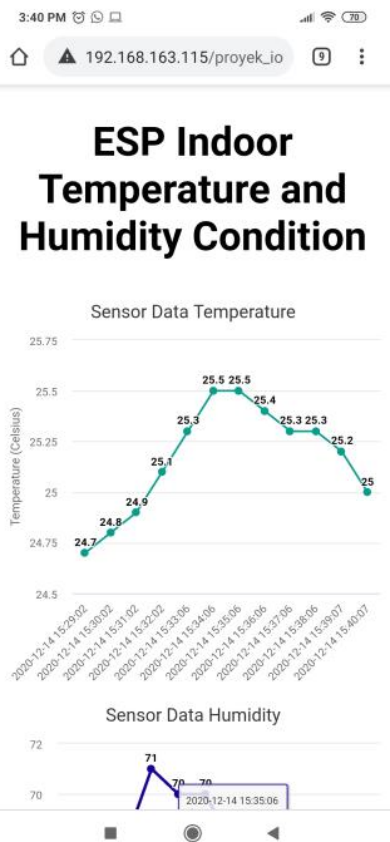

Gambar 5. Antarmuka Website di Perangkat Mobile 


\section{SIMPULAN}

Berdasarkan hasil uji coba dari implementasi teknik visualisasi melalui antarmuka website dapat disimpulkan bahwa teknik visualisasi dapat diimplementasikan ke dalam antarmuka webste untuk menampilkan data-data sensor yang sebelumnya telah disimpan di dalam basis data web server. Hasil dari visualisasi tersebut dapat dibaca berdasarkan indikator atau informasi dari grafi visual tersebut.

\section{DAFTAR PUSTAKA}

[1] Habibi, R. (2017). Perencanaan sistem smart academic dengan smart classroom dan teknologi internet of things pada stmik bina patria. Jurnal Transformasi, 13(1).

[2] Karim, A. B., Hassan, A. Z., \& Akanda, M. M. (2018). Monitoring food storage humidity and temperature data using IoT. MOJ Food Process Technol, 6(4), 400-404.

[3] Yuliantoro, P., Setiawan I. P., Alhazmi Q. (2019). Sistem Pemantauan Suhu Dan Kelembaban Ruangan Secara Real-Time Berbasis Web Server. Journal of Technology and Informatics (JoTI), 1(1), 56-60.

[4] Rohman, Q. A. H. H., \& Salahuddin, N. S. (2018). Rancang Bangun Prototipe Mobil Penjelajah Dengan Kendali Jarak Jauh Melalui Jaringan Wi-Fi Berbasis Antarmuka Web. Teknika, 7(1), 1-7.

[5] Shkurti, L., Bajrami, X., Canhasi, E., Limani, B., Krrabaj, S., \& Hulaj, A. (2017, June). Development of ambient environmental monitoring system through wireless sensor network (WSN) using NodeMCU and "WSN monitoring". In 2017 6th Mediterranean Conference on Embedded Computing (MECO) (pp. 1-5). IEEE.

[6] Mandarani, P. (2014). Perancangan Dan Implementasi User Interface Berbasis Web Untuk Monitoring Suhu, Kelembaban Dan Asap Pada Ruangan Berbeda Dengan Memanfaatkan Jaringan Local Area Network. Jurnal Teknoif, 2(2).

[7] Satria, D. (2017). Rancang Bangun Sistem Penjadwalan Bel Sekolah Berbasis Arduino Uno dengan Antarmuka Berbasis Web Menggunakan Ethernet Web Server. Jurnal Serambi Engineering, 2(1). 